\title{
ULTRA HIGH SPEED CAMERA INVESTIGATIONS OF LASER BEAM WELDING
}

\author{
Paper (501)
}

\author{
Ingemar Eriksson, John Powell, Alexander F. H. Kaplan \\ Luleå University of Technology, 97187 Luleå, Sweden
}

\begin{abstract}
With the help of high speed camera equipment, researchers can now directly observe melt flow phenomena which only could be imagined or simulated in the past. In this paper the motion of the molten metal inside the keyhole has been observed at frame rates as high as $180000 \mathrm{fps}$ to provide useful information about the laser beam welding process. This paper describes two different cases where high speed imaging has given new insights into the laser beam welding process: A. In pulsed welding the melt pool oscillations can create ripples on the solidified weld surface. With the help of a high speed camera this phenomenon was analyzed, and the pulse shape was adjusted to reduce the ripple amplitude to a minimum. B. In Zn-coated steel edge welding it could be seen that blowouts were sometimes created in the melt pool at some distance behind the keyhole. Direct slowmotion observation has led to the formulation of a phenomenological model of this effect.
\end{abstract}

\section{Introduction}

After the invention of photography, it wasn't long before a scientist realized the power of high speed photography. The first known case is the famous galloping horse published in 1887 by Eadweard Muybridge. Muybridge proved that, at certain points during a horse's galloping cycle, all the hoofs were in the air. These high speed images were created with one camera for every frame. This reduced the number of frames to the number of cameras, but the frame rate was theoretically unlimited. A problem with multiple cameras is that each camera will have a different point of view, and thus this technique is not suitable for micro photography.

High speed photography was quickly developed to high frame rates. In the 1930's a rate of 1000 frames per second (fps) was reached, and by introducing the rotating prism technique $40.000 \mathrm{fps}$ were achieved soon afterwards. By the conversion of photons to electrons, images could be stored on a phosphorescent screen. With electrical deflection to store the images on a phosphorescent screen frame rates over 100.000.000 were reached in the 1960s. Today digital
CCD and CMOS cameras dominate the high speed photography market. The cameras used in this paper save the image to an internal random access memory capable of storing several thousand frames. This enables us to capture a long sequence of high speed photographs to isolate the events which cause defects. By reducing the number of pixels saved in every frame the frame rate can be increased. But the practical frame rate is limited to a few hundred thousand frames per second.

The laser welding community has used the technology of high speed photography for a long time and, as the technology develops, phenomena can be observed in ever greater detail. To demonstrate the power of high speed photography we present here two different cases where the latest generation of digital cameras was used to provide interesting new information about the lasermaterial interactions which take place during laser welding.

\section{Ripples in spot welding}

The first example is an industrial case of laser spot welding of a titanium surgical implant. Surface ripples such as those shown in figure 1 were found on the finished weld. Ripples of this sort could be unacceptable because of their effect on the fatigue life or the visual appearance of the weld. In an experimental program which investigated the process of the ripple formation with high speed cameras, a strategy to minimize the effect was developed. The phenomenology of ripple formation was examined by high speed photography under high intensity illumination and the strategy for ripple minimization involved suitable power modulation of the laser pulse. Ripples were found to originate from the oscillations $[1,2]$ of the weld pool. As the weld pool solidifies rapidly $[3,4]$ the oscillations are frozen to become ripples on the surface. 


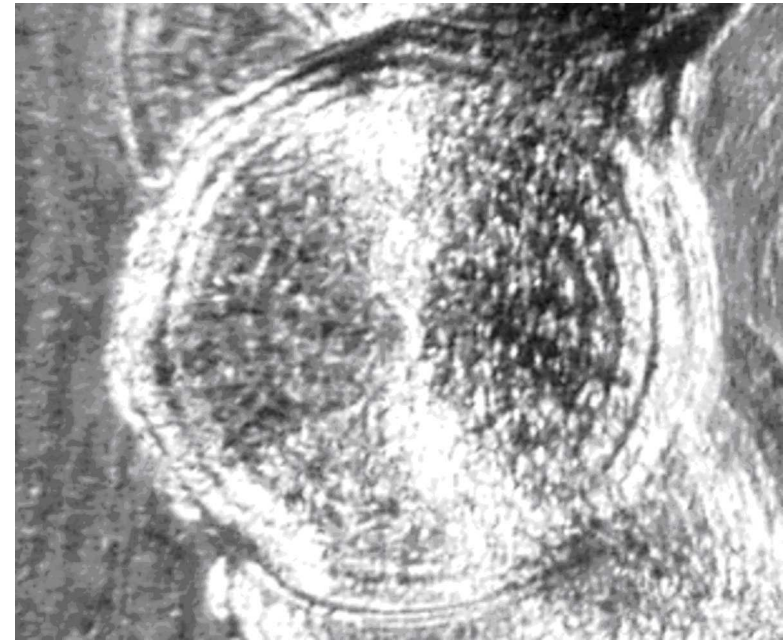

Figure 1. The rippled topography of typical pulsed laser weld in titanium.

The experiment involved pulsed Nd:YAG welding of titanium. The Laser used was a ROFIN-SINAR P500. The laser pulse was $\sim 1,5 \mathrm{~ms}$ long with a repetition rate of $5 \mathrm{~Hz}$ and $30 \%$ of the available pulse power. The welded part was moved between pulses to produce a weld seam of overlapping spot welds. The feed rate was adjusted to give $50 \%$ overlap of the pulses $(\sim 2 \mathrm{~mm} / \mathrm{s})$. The shielding gas employed was Argon. To observe the welding a Redlake X3 high speed camera at 8000 frames per second was used with a Cavilux illumination laser at a power of 500 Watts with $1 \mu \mathrm{s}$ illumination time. Figure 2 is a magnified view of the finished weld seam considered in this experimental program, showing the overlap geometry and the surface ripples on the individual spot welds.

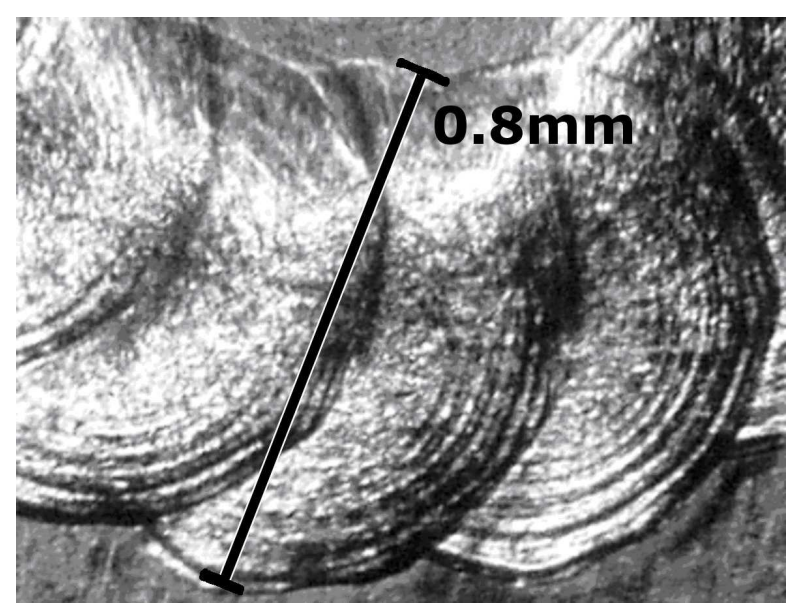

Figure 2. The overlap geometry of the spot welds investigated.

Examination of high speed filming shows that the melt pool oscillated with a frequency of approximately $3 \mathrm{kHz}$ and the time from turning off the laser to completely solid surface was $3 \mathrm{~ms}$. This rapid solidification froze the oscillations in the surface.

\section{High speed photography of ripple formation.}

Figure 3a-f presents a series of still photographs from high speed filming of the creation of a single pulse spot weld. A pulsed diode laser of $810 \mathrm{~nm}$ wavelength is utilized as illumination.

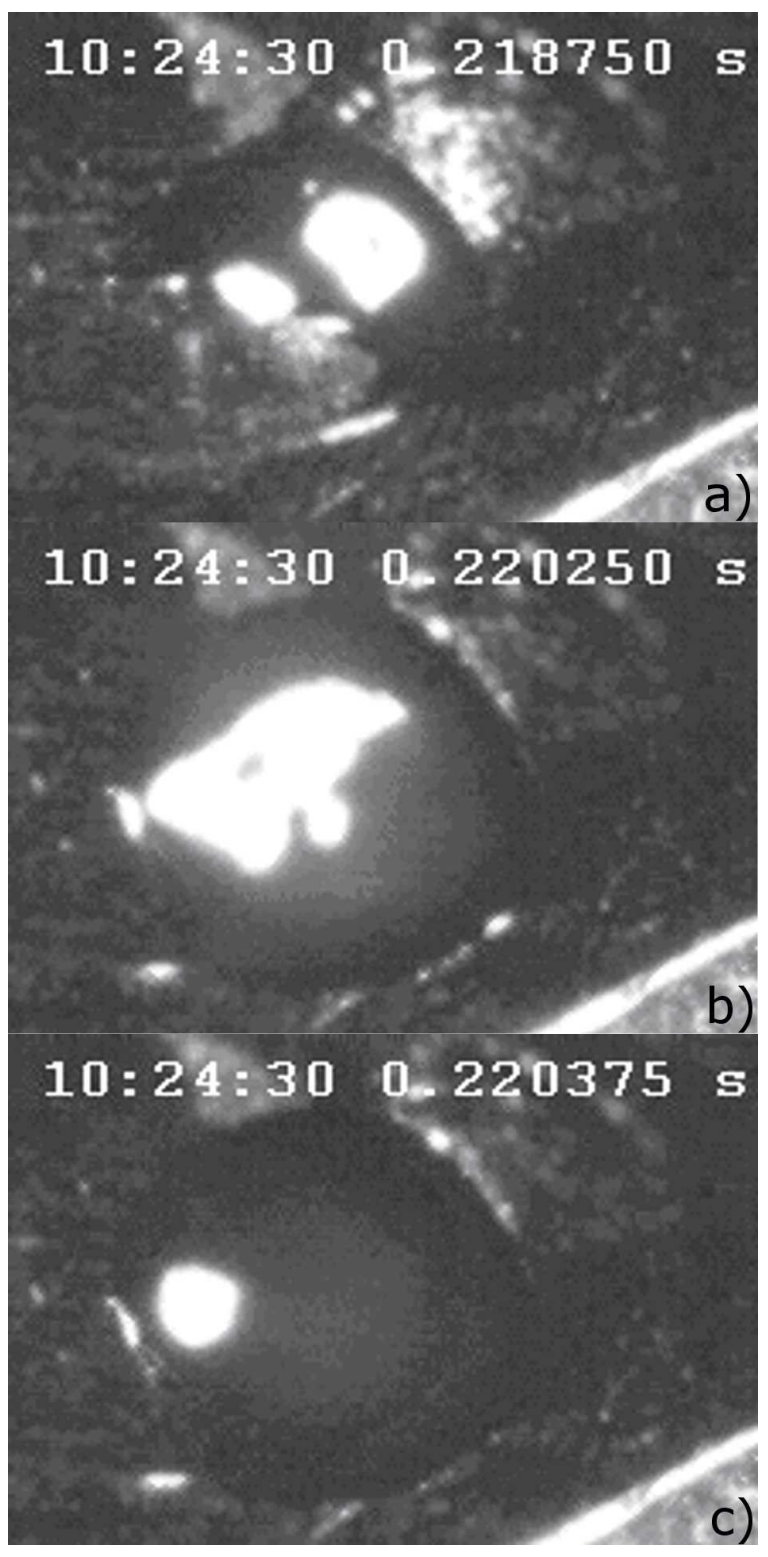




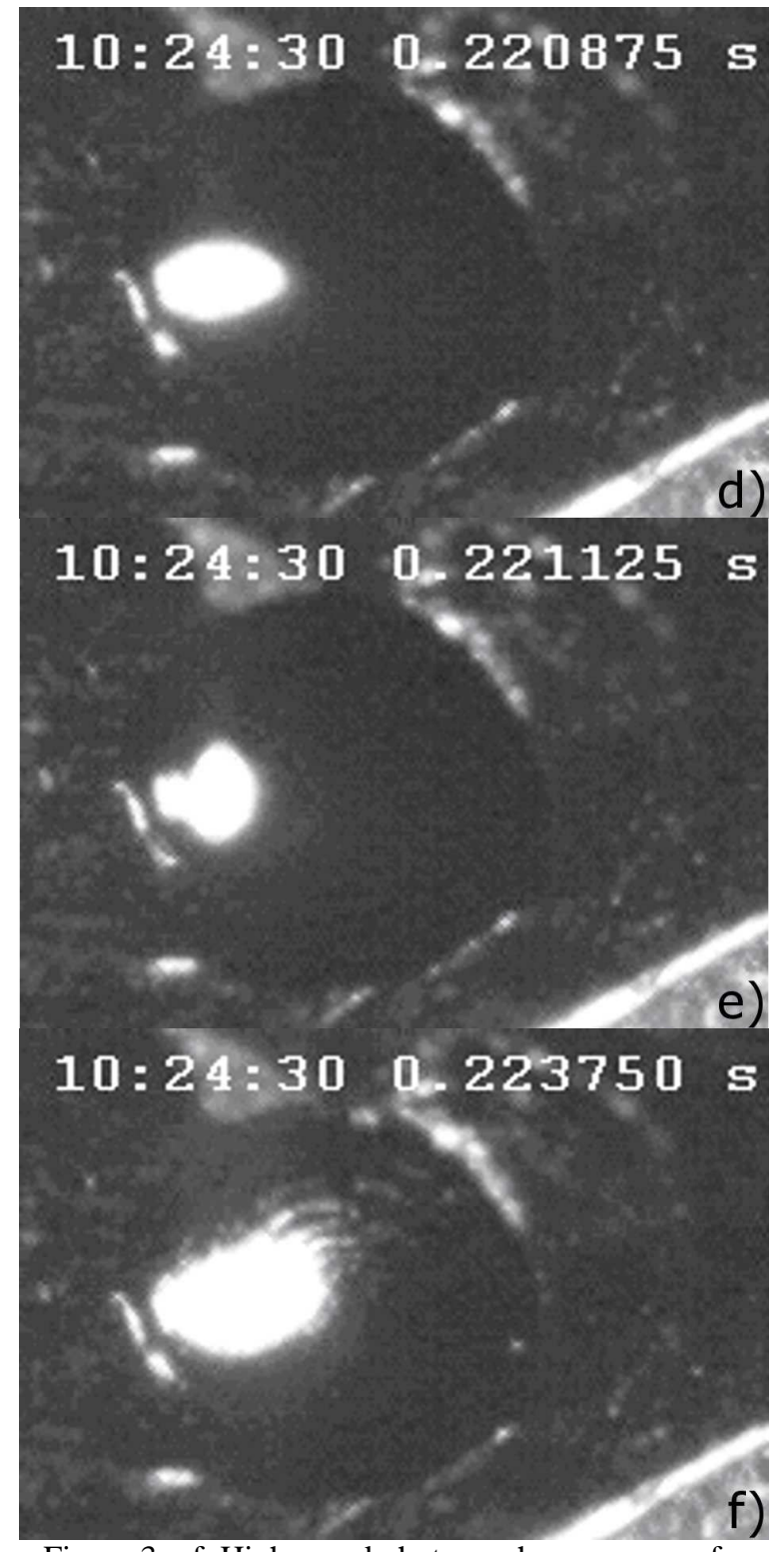

Figure 3 a-f. High speed photography sequence of a single spot weld creating surface ripples.

From this series of photographs it can be inferred that the progression of events which results in a set of concentric ripples on a single pulse spot weld is as follows;

- The laser pulse starts its interaction with the material and begins to melt the surface. (Figure 3a)

- The weld pool grows in volume and diameter as the laser continues to irradiate the surface. A depression forms in the middle of the weld pool as a result of localized boiling - which exerts a pressure on the melt. And the melt is pushed laterally away from the centre [5]. (Figure 3b)
- The laser pulse ends and boiling ceases (Figure 3c). Surface tension forces the melt to attempt to spring back from a concave geometry to a convex one. (Seen in figure $3 \mathrm{~d}$ as a horizontal elongation of the glare)

- The momentum of the melt in the direction perpendicular to its surface makes the melt surface overshoot its equilibrium position. The melt surface then assumes damped simple harmonic motion around its equilibrium position.

- The melt solidifies before this action has died down and the ripples are frozen into the surface topology of the weld (Figure 3e), and this generates surface ripples. (Figure $3 \mathrm{f}$ )

Pulse shape modulation to suppress ripple formation.

A series of experiments was carried out to establish the most effective pulse shape to minimize ripples in the eventual weld topology. The overall strategy was to extend the molten life of the melt so that the ripples could die away before solidification took place. Productivity was not affected by this technique because the original pulse frequency of $5 \mathrm{~Hz}$ was maintained - the post weld heating was accommodated in the gap between the pulses. The original $1.5 \mathrm{~ms}$ rectangular power profile of the weld pulse was extended at a lower power level as shown in figure 4 . Successful welds with minimum surface rippling were produced at an extended pulse lifetime of $4 \mathrm{~ms}$.

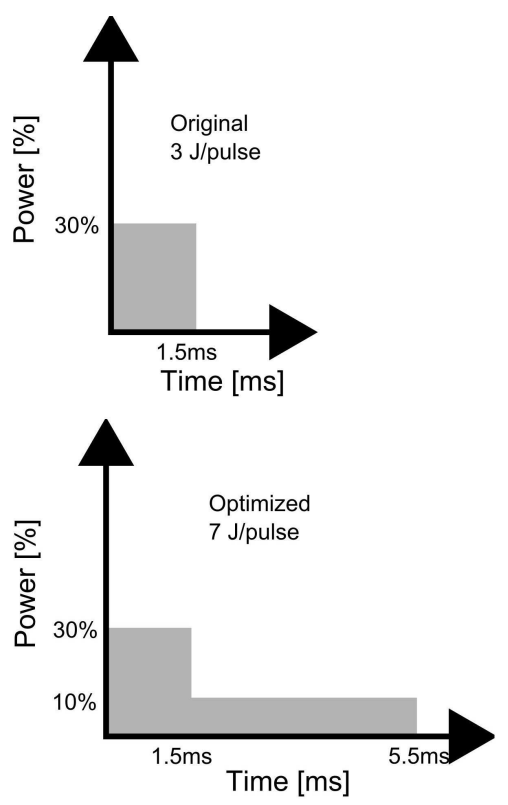

Figure 4. One strategy of pulse shaping to minimizes the surface ripples 
Figure 5 demonstrates that the majority of the surface ripple effect has been suppressed although there is some evidence of minor rippling at the edge of the solidified melt where cooling and solidification rates are at their highest.

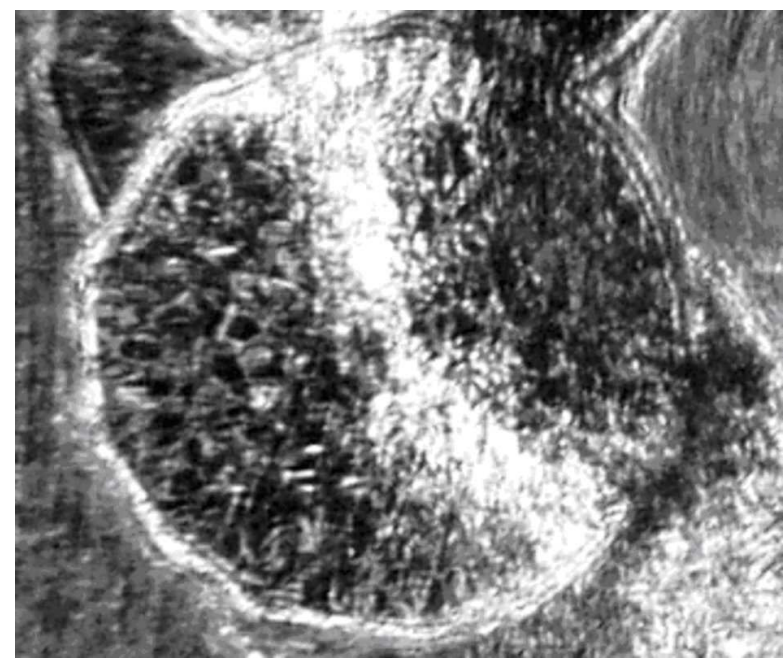

Figure 5. spot weld with minimal surface ripples.

(Different crystal orientations of the titanium can be seen on the smooth solidified surface.)

\section{Conclusions - ripple case}

In the latter stages of the laser-melt interaction during pulsed laser spot welding, the central portion of the weld is depressed as a result of localized boiling which exerts a pressure on the melt. As the laser pulse ends, the boiling ceases, and the pressure is removed. The melt then begins to return to its equilibrium geometry under the influence of surface tension, but the vertical momentum of the melt carries it past this equilibrium position. The surface then experiences damped simple harmonic motion. Ripples on the surface of the solid welds are created by rapid solidification of a surface which was undergoing damped simple harmonic motion. By delaying the solidification until the harmonic motion is completely dampened, surface ripples can be avoided.

\section{Zinc coated blow-out case}

The welding of Zinc coated steel plates is an important part of automotive manufacturing. A common problem during laser welding of zinc coated plates is that the zinc is evaporated; the zinc vapor causes blowouts and pores in the melt pool and produces holes in the weld seam. Several different solutions to the problem have been suggested and evaluated, but new methods are still being developed [6-9] and more knowledge about the process is needed.
With the help of high speed photography it can clearly be seen how the holes in the weld seam are created. Different types of blowouts can be categorized, [10]. Sometimes in the otherwise calm melt pool a blowout can appear. In figure 6 one of these blowouts is caught on film during the welding of a lap/edge joint in zinc coated steel. $(0.8 \mathrm{~mm}, 2.5 \mathrm{~kW} \mathrm{Nd}: Y A G, 100 \mathrm{~mm} / \mathrm{s})$

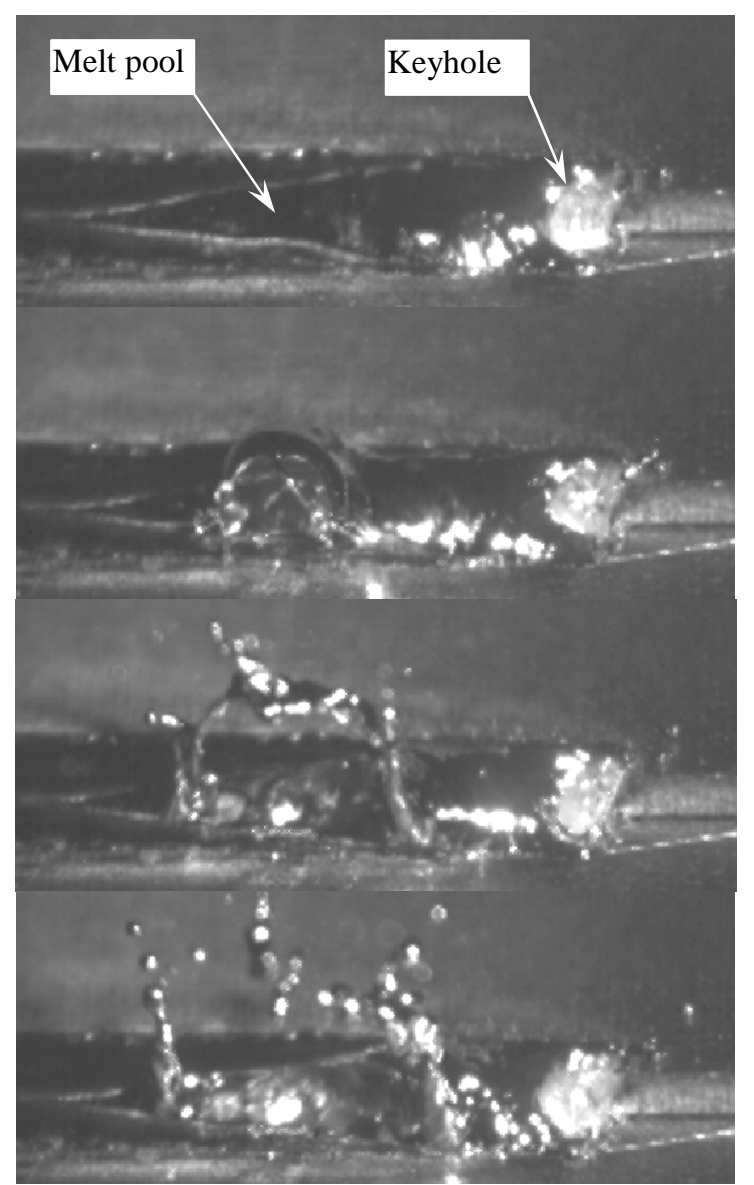

Figure 6. Blowout in melt pool at 2500fps

These big blowouts are the results of the escape of pressurized zinc gas accumulated in the melt pool. In figure 7 the internal pores along the weld seam show that zinc vapor is constantly pushed into the melt pool. Sometimes a pore reaches the surface and creates a small visible pore. But if the gas accumulates into large pores, there is a risk of material blowout when the surface tension cannot hold the pressure.

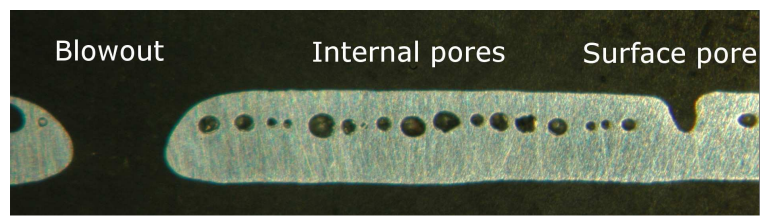

Figure 7. Cut along weld seam showing pore content. 
One way of eliminating this problem is to introduce a small gap $(0.1 \mathrm{~mm})$ in the joint, that enables the zinc gas to be evacuated, and no gas pressure is built up in the melt. But to maintain a constant gap of $0.1 \mathrm{~mm}$ in an automated production line can be difficult. Some researchers [11-12] have reported that pore-free zerogap welds are possible by pulsing the laser power. One theory is that, in this case, the zinc gas is evacuated through the keyhole capillary.

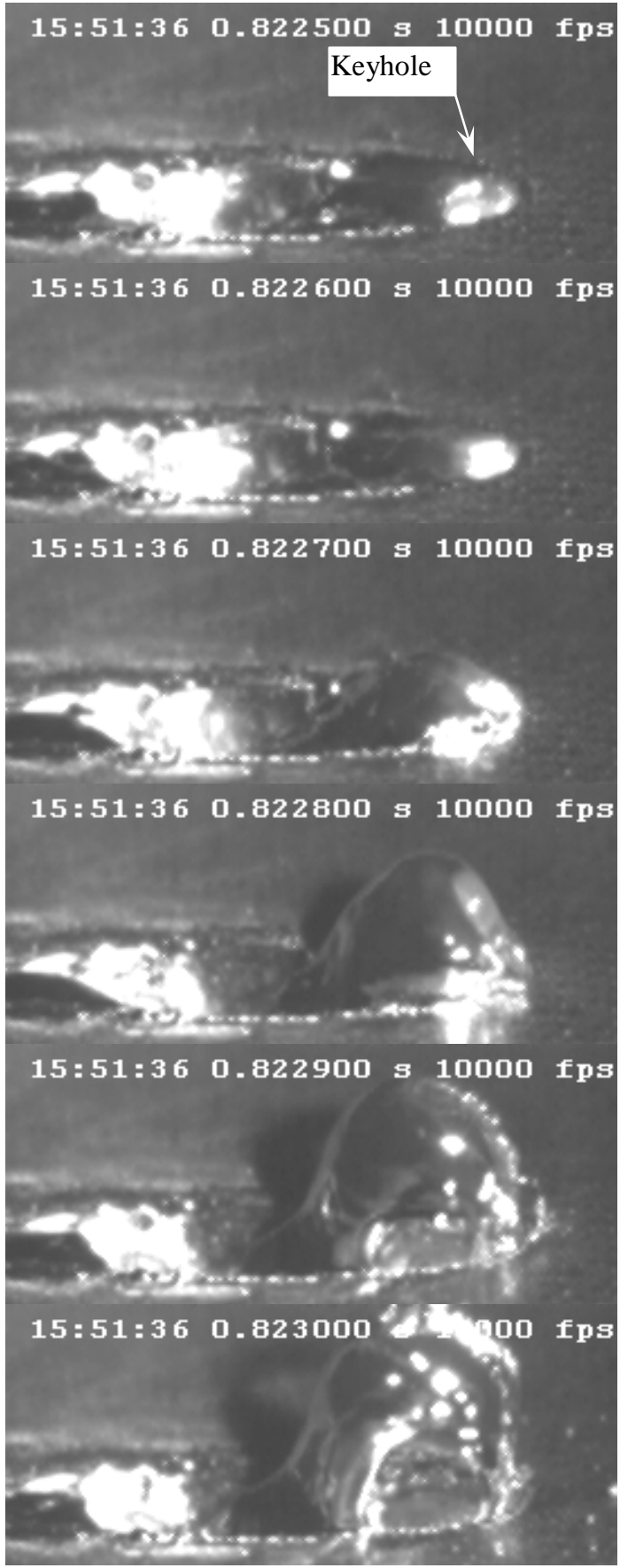

Figure 8. Blow out of the keyhole region

\section{$180000 \mathrm{fps}$ inside keyhole}

Figure 8 shows a sequence of high speed images where zero gap overlap welding provokes the entire melt pool to be blown out of the weld zone. This event made it possible for the second high speed camera we used to catch a glimpse of the front side of the keyhole for a moment (as in Figure 9a). This second camera was a Photron SA1 camera with a Micro-Nikkor $105 \mathrm{~mm}$ lens, running 180000 frames per second with an exposure time of $370 \mathrm{~ns}$. The image size was $128 \times 128$ pixels with 12 bit pixel depth. This back view camera was used without illumination so all the light collected was from heat radiation (Figure 9b). With this camera view it was possible to see a downward motion in the molten metal, and how the pressurized zinc gas sprays liquid metal away from the front wall of the keyhole.
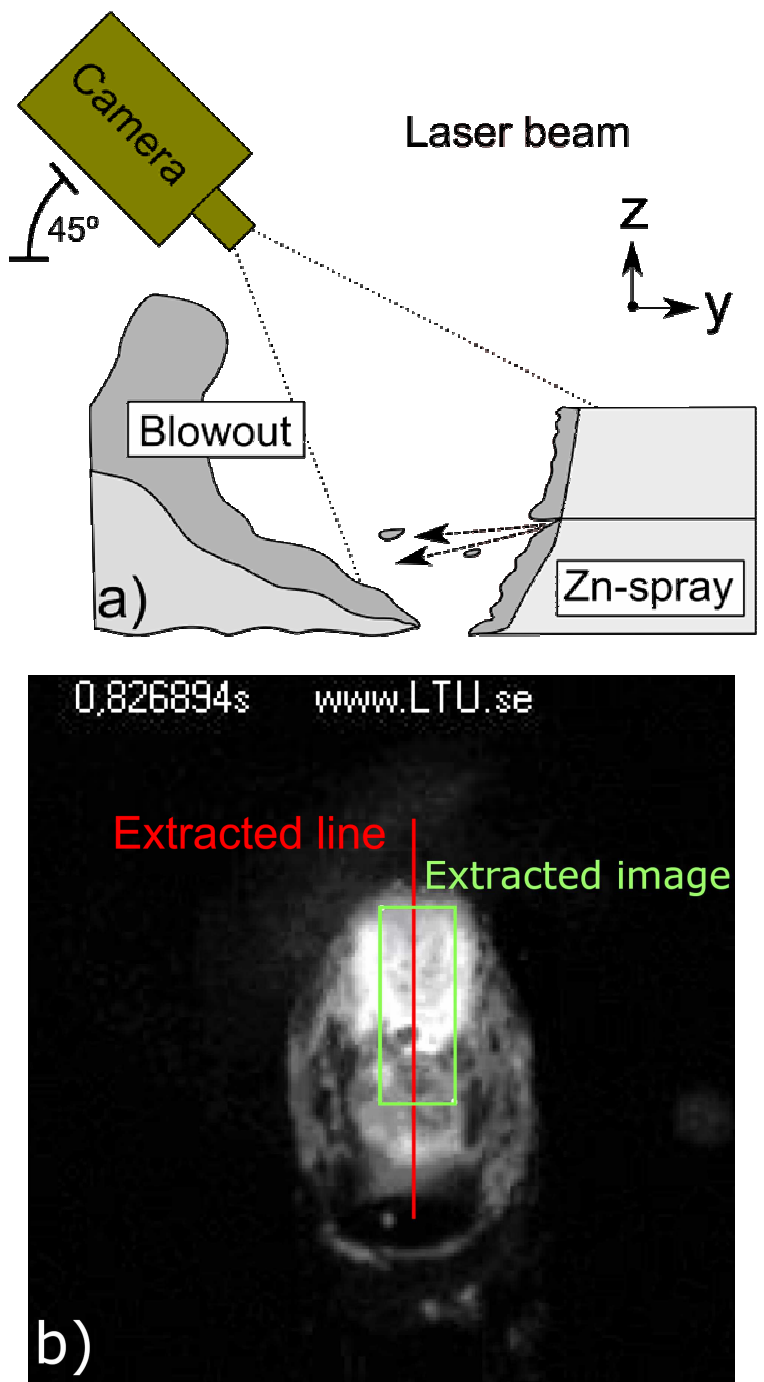

Figure 9. a) simplified geometry b) camera image 
In figure 10 a sequence of images (extracted from the area indicated in figure 9b) shows the ejection of droplets of molten metal. The gray scale level in these images is an indication of temperature, the bright areas are probably humps heated by the laser - having a higher temperature then the surroundings. A downward flow can be observed but as the surface changes over time a qualitative speed measurement is difficult.

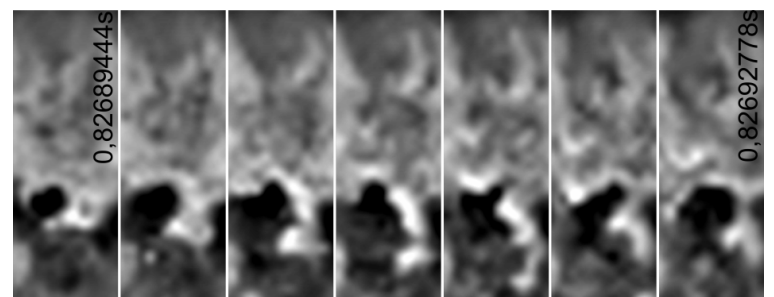

Figure 10. Front wall of keyhole, $33 \mu$ s long sequence.

To measure the speed a streak image technique can be utilized. A thin, central strip, one pixel wide, can be extracted from photographic images of the type shown in figure 9. A collection of these single pixel lines can then be placed side by side to present streak photo information mapping the movement of bright zones along the centre line of the main image. Figure 11 presents the data in this format, and shows the variation in brightness along the capillary centre line over time.

In figure 11 a total number of 540 frames have been arranged in this way and it is clear that in the center of the keyhole front there is a constant $7 \mathrm{~m} / \mathrm{s}$ motion downwards of bright areas. The dark horizontal band in figure 11 is the gap between the two welded plates where the zinc gas escapes. Molten metal from the upper sheet flowing over the gap sometimes creates spatter. The movement of this spatter can be observed as thin bright lines at the bottom of figure 11 and speeds vary from $5 \mathrm{~m} / \mathrm{s}$ to $15 \mathrm{~m} / \mathrm{s}$.

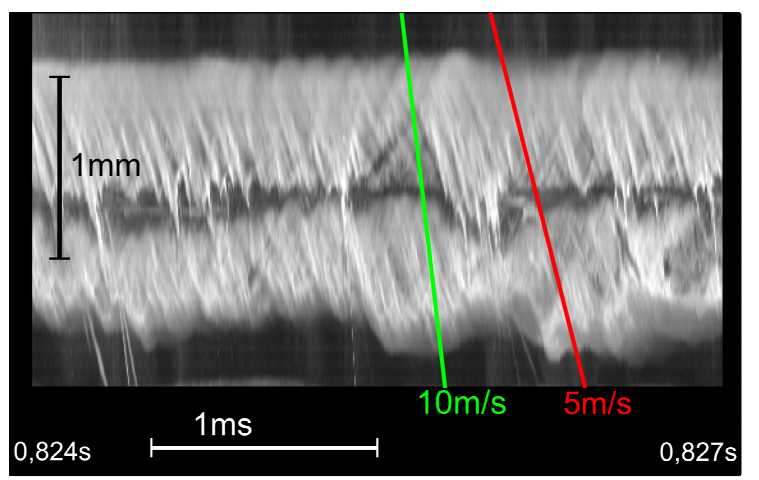

Figure 11: Streak image of keyhole front

\section{Conclusions - zinc coated blow-out case}

As the automotive industry has invested a lot in research about laser welding of zinc coated material, much is already known or assumed to be known. With the help of new high speed camera equipment the physical behaviour of the melt during the welding can be observed directly, and theories about the welding process can easily be confirmed or dismissed. As we have show in this paper, the pressurized zinc gas can create blow-outs in the melt pool, or create internal pores that weaken the weld strength. We also show that zinc gas can enter the keyhole capillary and exit the weld this way, (but in our experimental case the high speed of the zinc gas blows away the melt pool).

With the welding settings we used $(2.5 \mathrm{~kW} \mathrm{Nd:YAG,}$ $100 \mathrm{~mm} / \mathrm{s}$ ) there was a constant downward flow of what looks to be humps on the front wall of the keyhole. Similar to that described by Matsunawa and Semak in 1997 [13]. This type of flow happens continuously, but is visible but only when the melt pool has been blown away and the entire front of the keyhole is visible. The possibility to measure this flow experimentally could help in calibrating simulation models of this effect.

\section{General conclusions}

Even though some laser researchers have been using high speed cameras for a long time, the recent development of the equipment has enabled easier use. The cameras can be used in industrial installations and help to develop our understanding of the process. (The ripple case was filmed in an industrial production line on a commercial product.)

The ability to view and measure the metal flow inside the keyhole will be of great help in explaining the mechanisms of laser welding in the future. As the number of research facilities with high speed cameras is increasing, new methods of real time measurement will be used to improve theoretical models.

\section{Acknowledgements}

This work was founded by VINNOVA as a part of the DATLAS project. (no: 2005-02895)

The authors are also grateful at Rickard Olsson and Ove Sundelin at Lasernova AB in Östersund for their support in the experimental work. 


\section{References}

[1] Cho J, Farson D, Milewski J \& Hollis K (2009) Weld pool flows during initial stages of keyhole formation in laser welding Journal of Physics DApplied Physics 42175502

[2] Klein T, Vicanek M \& Simon G (1995) Forced oscillations of the keyhole in penetration laser beam welding Journal of Physics D-Applied Physics 29 322332

[3] He X, Elmer J W \& DebRoy T (2005) Heat transfer and fluid flow in laser microwelding Journal of applied physics 9784909

[4] He X, Fuerschbach P W \& DebRoy T (2003) Heat transfer and fluid flow during laser spot welding of 304 stainless steel Journal of Physics D-Applied Physics 36 1388-1398

[5] Semak V V, Knorovsky G A, MacCallum D O \& Allen Roach R (2006) Effect of surface tension on melt pool dynamics during laser pulse interaction Journal of Physics D-Applied Physics 39 590-5

[6] Bley, H Weyand, L \& Luft, A (2007) An alternative approach for the cost-efficient laser welding of zinc-coated sheet metal, Annals of the CIRP 56 pp. 17-20.

[7] Li X, Lawson S, Zhou Y, \& Goodwin F. (2007) Novel technique for laser lap welding of zinc coated sheet steels. Journal of Laser Applications 2007;19:259-64.

[8] Iqbal S, Gualini M \& Rehman A, (2010) Dual beam method for laser welding of galvanized steel: Experimentation and prospects, Optics \& Laser Technology 42 93-98,

[9] Chen W, Ackerson P \& Molian P, (2009) CO2 laser welding of galvanized steel sheets using vent holes, Materials \& Design, 30 245-251

[10] Norman, P. Eriksson, I. \& Kaplan, A. F. H. (2009) Monitoring laser beam welding of zinc coated sheet metal to analyse the defects occurring, in Proceedings of the NOLAMP-conference, Copenhagen, Denmark,

[11] Yih-fong T. (2006) Gap-free lap welding of zinc coated steel using pulsed $\mathrm{CO}_{2}$ laser, Int. journal of Advanced Manufacturing Technology 29 287-295.

[12] Heydon J, Nilsson K, Magnusson C (1989) Laser welding of zinc coated steel. In: Proceedings of the 6th
International Conference on Lasers in Manufacturing, pp 93-104

[13] Matsunawa A. and Semak V. (1997) The simulation of front keyhole wall dynamics during laser welding. Journal of Physics D-Applied Physics 30798

\section{Meet the Authors}

Ingemar Eriksson was born in Östersund, Sweden in 1980. He studied Electrical Engineering at the Mid Sweden University from 2001 to 2005. Since 2008 he has been employed at Luleå University of Technology as a $\mathrm{PhD}$ student in laser welding.

Dr. John Powell has been active in laser processing research since the 1980's. He is the author of two books on laser cutting and over 100 papers on laser processing. He is a visiting professor at Luleå University of Technology.

Alexander Kaplan was born in Vienna, Austria in 1967 and employed as researcher at Vienna TU from 1989 until 2000. He received a PhD in 1994 on modeling of laser welding. After a post-doc year at Osaka University, Japan, from 2002 on he has been appointed as professor and head of division on manufacturing at Luleå University of Technology, Sweden. His research focus comprises laser materials processing, in particular process modeling, laser welding and hybrid welding. 